\title{
ECOLOGIA DO HOMEM: MÉTODO ALTERNATIVO DE DESSENSIBILIZAÇÃO DA GLANDE PARA O CONTROLE EJACULATÓRIO
}

\author{
ECOLOGY OF MAN: ALTERNATIVE METHOD OF PENILE GLANS \\ DESENSITISATION FOR THE EJACULATORY CONTROL
}

\begin{abstract}
Resumo
O corpo é o palco da natureza humana, conhecê-lo, desbravá-lo é primordial para o autoconhecimento e para sua preservação enquanto microuniverso da ecologia individual. Esse trabalho descreve os procedimentos de uma técnica de massagem íntima, chamada pelo autor de "método alternativo de dessensibilização da glande" como sugestão de recurso para o autocontrole da ejaculação (precoce) e, sobretudo para a promoção do processo de autoconsciência corporal. As reflexões e hipóteses parciais desta pesquisa fundamentam-se em referenciais teóricos da ecologia humana, em conceitos da biologia e da psicologia reichiana. Descartadas todas as hipóteses de condições fisiológicas/patológicas ou psíquicas/ neuróticas graves, (incluindo a disfunção erétil) o referido método pode em muitos casos oferecer aos usuários de atividade sexual ativa avanços significativos sobre o controle ejaculatório, prolongando a capacidade de penetração durante as relações sexuais. Por assemelhar-se a uma manobra masturbatória, a técnica não oferece riscos à saúde do usuário e pode ser facilmente sugerida durante consultas de orientação sexual, em clínicas de psicologia, sexologia e urologia.
\end{abstract}

Palavras-chave: Controle ejaculatório. Ecologia humana. Consciência corporal.

\begin{abstract}
The body is the field of human nature, to know it, discover it, is paramount for self-knowledge and for its preservation as a microuniverse of individual ecology. This paper describes the procedures of an intimate massage technique, called by the author of "alternative method of desensitisation of the penile glans", as a suggestion of recourse to self-control of ejaculation (precocious) and, above all, to promote the process of body self-consciousness. The reflections and partial hypotheses of this research are based on theoretical references of human ecology, concepts of biology and Reichian psychology. If all hypotheses of severe physiological/ pathological or psychic /neurotic conditions (including erectile dysfunction) are discarded, the method may in many cases offer users of active sexual activity significant advances in ejaculatory control, prolonging the penetration capacity during intercourse Sexual relations. Because it resembles a masturbatory maneuver, the technique offers no risk to the user's health and can easily be suggested during sexual orientation consultations, in psychology, sexology and urology clinics.
\end{abstract}

Keywords: Ejaculatory control. Human ecology. Corporal conscience.

\footnotetext{
Alisson José Oliveira Duarte

Universidade Federal do Triangulo Mineiro.

E-mail: alisson-duarte@hotmail.com
} 


\section{Introdução}

"O excesso de animalidade deforma o homem cultural; o excesso de cultura cria animais doentes". (JUNG, 2011a, p.39).

O século XXI, juntamente com o advento da globalização, trouxe grandes mudanças em diversos níveis da vida social e até mesmo sobre o comportamento sexual dos indivíduos. "No final dos anos 60 , o sexo inicia sua emancipação da essencialidade e da reprodução". As verdades impostas sobre os conceitos de sexualidade começaram a ser questionadas pelos movimentos feministas e homossexuais que contribuíram para a disseminação de estudos no campo das ciências humanas e sociais. "O discurso construcionista redefiniu o gênero e a identidade sexual, separou a identidade das práticas sexuais, questionou o determinismo biológico, construiu a história da homossexualidade" e desconstruiu a tradicional dominação masculina (PAIVA, 2008, p.644).

Nesse cenário, os holofotes dessa pesquisa serão lançados, sobretudo no que concerne aos reflexos dessas mudanças sociais sobre a sexualidade masculina e especificamente em relação ao surgimento do chamado "transtorno de ejaculação precoce", apontado na categoria F52.4 do livro de Classificação Internacional de Doenças (CID-10) e no Manual Diagnóstico e Estatístico de Transtornos Mentais - DSM V, no qual define-se os critérios diagnósticos para a ejaculação precoce desde a década de 1980 (NOVARETTI, 2002). No entanto, somos de acordo com Rodrigues Jr. (2004, p.183) que "os critérios para a definição da ejaculação precoce sempre foram imprecisos", sofrendo variações conforme o percurso temporal, bem como em relação ao lócus cultural dos indivíduos.

Sabemos que desde tempos imemoráveis, a sexualidade cumpre papel importantíssimo à vida emocional do homem, tanto em relação à constituição de sua autoimagem, como de sua identidade social. Se a vida sexual de um indivíduo do sexo masculino é de qualquer forma afetada, possivelmente ele poderá experimentar intrinsecamente sentimentos de crise de identidade e/ou de rebaixamento de sua autoestima (BEN-ZION, et al, 2004).

De acordo com Abdo et al. (2002) e Martins (2007) cada vez mais tem se tornado recorrente o número de homens que têm buscado auxílio de profissionais da saúde com a finalidade de solucionar questões de ordem sexual.
Conforme os autores, as queixas mais frequentes giram em torno de preocupações quanto à forma anatômica do órgão sexual, dificuldade de ereção e ejaculação precoce que segundo Novaretti (2002) é o transtorno sexual mais comum entre os homens.

A saga pelo orgasmo feminino e a responsabilização, muitas vezes indiretamente atribuída, ao sexo masculino pelo seu acontecimento, tem feito homens heterossexuais e bissexuais cada vez mais se preocupar com seu desempenho sexual em termos quantitativos (duração da capacidade de coito e condição física para a repetição contínua do ato sexual).

Essa demasiada preocupação em parte advém das reivindicações feministas da modernidade e da superação dos velhos paradigmas, onde, sobretudo no passado, o exercício da sexualidade masculina repousava tranquilamente sobre o comodismo de não se preocupar com o prazer feminino (PAIVA, 2008). Aliás, sob o julgo da mentalidade machista dos séculos passados, o prazer feminino foi considerado tabu pelos homens e muitas vezes pelas próprias mulheres.

Evidentemente a preocupação masculina em torno do controle ejaculatório não se observa somente entre os casais heterossexuais, como também vem sendo alvo de preocupação entre os casais homossexuais (GROSSI, et al., 2015). Fato que nos leva a reflexão de que a imagem socialmente construída do "bom amante" (além de outros atributos como carinho, atenção, dedicação e status) tem sido também atribuída a sua capacidade de controle ejaculatório.

O presente estudo descreve os procedimentos de uma técnica de massagem íntima, que chamamos de "método alternativo de dessensibilização da glande" como sugestão de recurso para o autocontrole do reflexo ejaculatório e, sobretudo para a promoção do processo de autoconsciência corporal. Conforme Polak (1996) "é necessário romper com o pensamento racionalista, com as dicotomias corpo-mente, corpo-espírito, e ver o corpo como corporeidade, como o ponto de partida de toda e qualquer reflexão sobre o homem" (p.6). Segundo ela, "o corpo é a verdadeira constatação da existência humana" (p.9) e deve ser concebido como totalidade. Nessa perspectiva, o corpo revela a concretude sobre a realidade do indivíduo, nada melhor do que ele para explicar a ambiguidade do homem: corpo político, corpo social, consciência encarnada, consciência transcendental, "essência etérea, ser ontológico, mas ser bruto, ser selvagem" 
(p.21). De acordo com Merleau-Ponty (1973, p.133) “a carne é um elemento do ser, temos não um corpo e sim uma carne que sofre quando ferida, e mãos que apalpam (...); o corpo envolve uma filosofia da carne como visibilidade do invisível".

Buscamos também com esse estudo, contribuir com a superação da lacuna de estudos voltados para a compreensão da dificuldade de controle ejaculatório que tem reduzido à qualidade de vida de muitos casais e, sobretudo, a autoestima de homens que se sente angustiados por não conseguir corresponder a todas as características do "amante competente", fantasiado pelas atuais sociedades e pela mídia pornográfica (MARTINS, 2007).

Aliás, é primordial ressaltar que neste trabalho, não consideramos o fenômeno da ejaculação rápida, uma disfunção patológica ou um estado de adoecimento da sexualidade masculina. Mas antes, uma pseudo-condição patológico criada, produzida e inventada pela modernidade. Por muitos anos, cientistas estudaram o assunto e descobriram que não há uma causa específica para ocorrência da ejaculação inesperada, mas sim, uma combinação de fatores biopsicossociais (RODRIGUES JR., 2004).

Conforme Bestane et al (2002, p.88) o sexólogo Alfred Kinsey (1948) opinava que:

A capacidade de controlar o processo jaculatório apresenta variações normais entre as diferentes espécies animais e mesmo entre indivíduos da mesma espécie. Em muitos vertebrados superiores, a ejaculação ocorre imediatamente ou poucos segundos após a penetração vaginal. Tal característica não impede a função reprodutiva e pode até mesmo ser útil em alguns casos. Dentro deste raciocínio, a falta de controle ejaculatório não seria uma disfunção ou doença, mas tão somente a variação normal de uma característica dentro da espécie.

Por razões críticas, preferimos neste trabalho tratar a ejaculação rápida como um transtorno e não como uma disfunção. Isso porque, por transtorno, entendemos como uma condição socialmente construída e que em outros tempos não era considerada um empecilho. Enquanto disfunção nos remete a uma condição fisiológica e até mesmo patológica que impede o perfeito funcionamento da fisiologia humana.

Despatologizar o fenômeno da ejaculação inesperada é o primeiro passo para a resolução do problema ou daquilo que muitos homens e mulheres consideram um problema. Em se tratando de reflexo ejaculatório cada homem é natural em seu tempo e em sua singularidade. Mas se desejamos ou temos a necessidade de atender alienadamente as demandas sociais de normalidade, a despeito daquilo que é natural, mas em nome da qualidade de vida dos indivíduos que se sentem emocionalmente fragilizados por não corresponder aos padrões, este trabalho sugere um método alternativo, não invasivo para o controle ejaculatório, tanto para homens que se enquadram como ejaculadores precoces pelos critérios diagnósticos, quanto para aqueles que por motivos pessoais desejam prolongar sua capacidade de autocontrole.

Com as proposições do estudo, não pretendemos desmotivar pacientes à descontinuação do uso de antidepressivos, ansiolíticos, acompanhamentos médicos ou psicoterápicos que tenham por finalidade solucionar transtornos do controle ejaculatório. O método deve ser concebido como sugestão alternativo/coadjuvante, uma vez que a ejaculação prematura em sua complexidade pode ser atribuída a uma diversidade de fatores, entre eles: emocionais (tais como ansiedade, depressão, estresse), valores sociais e condições fisiológicas (genéticas ou patológicas).

De outro modo, frisamos que não temos a pretensão de oferecer um tratamento para ejaculação rápida, pois como já dissemos não partimos da hipótese de que o descontrole ejaculatório seja uma condição patológica. Preferimos chamar os procedimentos expostos neste estudo de "método alternativo de dessensibilização da glande" para o controle do reflexo ejaculatório. Alertamos que não basta que os procedimentos, que serão apresentados neste estudo, sejam executados algumas vezes para se oferecer uma "cura" integral aos usuários. Isto é, não nos proporemos à cura, mas a uma sugestão de saída para amenizar os possíveis prejuízos à vida afetiva dos diferentes casais heteroafetivos e homoafetivos que se sentem incomodados frente à condição da ejaculação rápida. Portanto, o método deverá ser repetido de acordo com a vontade dos usuários antes das relações sexuais.

Descartadas todas as hipóteses de condições fisiológicas/patológicas ou psíquicas/ neuróticas graves, (incluindo a disfunção erétil) o referido método poderá em muitos casos oferecer aos usuários de atividade sexual ativa avanços significativos sobre o controle ejaculatório, prolongando a capacidade de penetração durante as 
relações sexuais.

Por assemelhar-se a uma manobra masturbatória, a técnica não oferece riscos à saúde do usuário e pode ser facilmente sugerida durante consultas de orientação sexual, em clínicas de psicologia, sexologia e urologia.

Consideramos, dentro de uma perspectiva da ecologia humana e ecologia profunda, que o corpo é o palco da natureza humana, conhecê-lo, desbravá-lo é primordial para o autoconhecimento e para sua preservação enquanto microuniverso da ecologia individual (DUARTE, 2017).

\section{Método alternativo de dessensibilização da glande}

O presente estudo não visa aprofundar sobre as causas etiológicas da ejaculação precoce, nem suas classificações, definições e controvérsias já discorridas em inúmeros trabalhos. O objetivo primordial deste estudo é apresentar reflexões acerca do procedimento de controle ejaculatório que nos propomos com vistas no pensamento da ecologia humana. De início, é importante informar que o método se baseia em um procedimento muito parecido e próximo de um processo masturbatório comum, no qual o indivíduo utiliza-se de lubrificante e as próprias mãos ou as mãos de um(a) parceira(o) sexual para a execução de um procedimento de (auto)massagem genital.

A simplicidade do procedimento, de início parece trivial ou sem qualquer valor terapêutico, mas quando analisamos estudos, sobre terapia corporal, já existentes e relatados na literatura científica, deduzimos que o método pode oferecer suporte, como tratamento coadjuvante, no controle da ejaculação prematura:

Conforme Novaretti (2002, p. 311) o manejo terapêutico da ejaculação precoce pode ser feito com ou sem o uso de drogas que retardam a ejaculação. O tratamento não medicamentoso tem sido feito com psicoterapias e a utilização de treinamentos corporais.

Nesse sentido, Favorêto (2002, p.323-324) "acredita que a abordagem corporal tem muito a contribuir" no processo terapêutico para o controle da ejaculação prematura. Através da prescrição de exercícios objetiva-se "aproximar o indivíduo de suas sensações e sentimentos", interrompendo o processo de somatização decorrente de bloqueios emocionais. A autora observou que seus pacientes quando submetidos à "abordagem corporal, como uma técnica coadjuvante à terapia sexual", obtinham melhores resultados. Isto é, “além das sessões psicoterapêuticas, o paciente deverá realizar exercícios corporais e sexuais" como método de dessensibilização do reflexo ejaculatório.

De acordo com estudos em torno da ecologia humana e ecologia profunda, realizados por Duarte (2017), as neuroses psicossomáticas — assim como em alguns casos de descontrole ejaculatório — fazem parte de um processo natural de autorregulação psíquica e não devem ser eliminadas sem que sejam compreendidas dentro de suas funções potenciais, ou seja, para o autor os sintomas neuróticos teriam a função de levar os indivíduos à expressão máxima de sua espontaneidade, livre tanto quanto possível de máscaras sociais. Jung (2011a, p.30) afirma que a neurose surge com o processo de domesticação social, sendo "o neurótico apenas um caso específico de pessoa humana tentando conciliar dentro de si natureza e cultura".

Nesse sentido, nos casos em que a ejaculação rápida estiver notadamente vinculada a condições psíquicas e emocionais, sugerimos que o usuário mesmo tendo alcançado o controle ejaculatório com os procedimentos que serão apresentados, não se esqueça de buscar conhecer a si mesmo, a fim de não negar as trilhas do processo de autoconhecimento ditadas e sugeridas por sua natureza inconsciente através de sua condição fisiológica. Podendo para tanto utilizar-se de psicoterapia, práticas de meditação, imaginação ativa ou de processos autônomos de autorreflexão. Tais recursos de autoconhecimento, não deverão ser pautados unicamente no objetivo de eliminar sintomas, devendo, além do mais, direcionar o paciente a uma renovação de atitude frente à própria vida (DUARTE, 2017; JUNG, 2011).

Conforme Cândido e Mattos (2009) William Reich (1897-1957) foi pioneiro a identificar que as emoções e o estresse podiam gerar tensões sobre o corpo humano, introduzindo procedimentos de massagem como recurso (psico) terapêutico para desfazê-las. Reich (1998) chamou essas tensões ou núcleos de energia estagnada de couraças musculares. O autor também é conhecido por ser o precursor da terapia bioenergética que se utiliza de conceitos de couraça muscular, vegetoterapia e técnicas corporais entre elas grounding, respiração e massagem como procedimentos de intervenção psicoterapêutica.

No mesmo sentido Cândido e Mattos (2009) afirmam que o termo "bioenergética" faz parte do jargão reichiano que significa "energia biológica". Essa teoria 
parte do princípio de que corpo e mente são funcionalmente idênticos, isto é, o que ocorre na mente é o que ocorre no corpo e vice-versa. Para Barros (2002) tal conceito vai de encontro com o modelo holístico (do grego, holos $=$ integral, pleno) de saúde que visa englobar os aspectos biopsicossociais do ser humano.

Seguindo as concepções de Reich (1998) a couraça muscular funciona como uma espécie de encapsulação da energia vital impedindo-a de circular naturalmente pelo corpo. A couraça em outros termos pode ser descrita como um nódulo de tensão que se acumula em certas regiões do corpo e que frequentemente representam a repressão de emoções como raiva, medo, estresse e ansiedade. A bioenergética ou vegetoterapia visam liberar a couraça muscular dos pacientes, por meio de psicoterapia e técnicas de massagem local. Cândido e Mattos (2009) afirmam que o "objetivo da análise bioenergética é reequilibrar o paciente, desbloquear a circulação, em geral carregada de repressões, de tal forma que ao longo da terapêutica ocorra auto-percepção".

Kaplan (1984) propõe que os exercícios corporais sejam preferencialmente assistidos ou executados em parceria, isto é, contando com a colaboração do casal. Nesse sentido, o método de dessensibilização da glande pode ser executado tanto pelo usuário como por sua/seu parceira(o) sexual antes das penetrações.

\subsection{Procedimentos de execução do método}

Descartadas as hipóteses fisiológicas ou causas comprovadamente orgânicas que justifiquem o descontrole ejaculatório do paciente, o terapeuta sexual psicólogo, clínico geral, urologista, psiquiatra, sexólogo — poderá prescrever como sugestão de intervenção única ou coadjuvante o método de dessensibilização da glande, conforme 5 (cinco) notas explicativas, estabelecidas para a execução do procedimento de (auto) massagem íntima:

\begin{tabular}{|c|c|}
\hline \multicolumn{2}{|r|}{ MÉTODO ALTERNATIVO DE DESSENSIBILIZAÇÃO DA GLANDE } \\
\hline $\begin{array}{c}\text { I } \\
\text { Preparo } \\
\text { instrumental }\end{array}$ & $\begin{array}{l}\text { O usuário minutos antes de uma relação sexual (penetração vaginal ou anal) deverá oferecer a glande de } \\
\text { seu membro alta quantidade de estímulo. Isso deverá ser feito utilizando lubrificante íntimo apropriado em } \\
\text { abundância, aplicado sobre as próprias mãos ou sobre as mãos da(o) parceira(o). }\end{array}$ \\
\hline $\begin{array}{l}\text { II } \\
\text { Exposição da } \\
\text { Glande }\end{array}$ & $\begin{array}{l}\text { Com uma das mãos o usuário ou sua/seu parceira(o) deverá puxar o prepúcio do pênis para baixo (imobilizando } \\
\text { totalmente a pele do pênis) e deixando tanto quanto possível a glande exposta. }\end{array}$ \\
\hline $\begin{array}{c}\text { III } \\
\text { Estimulação }\end{array}$ & $\begin{array}{l}\text { Com a outra mão, sem fazer movimentos de sobe e desce ou de bombeamento (clássicos da masturbação } \\
\text { masculina) o usuário ou sua/seu parceira(o) deverá estimular com intensidade a cabeça do pênis, friccionando-a } \\
\text { de diferentes formas com a mão. Isso fará o usuário sentir uma alta quantidade de prazer, às vezes tão intensa, } \\
\text { que poderá provocar um estado de leve agitação motora. Os movimentos deverão ser contínuos e tanto quando } \\
\text { possível sem pausas durante aproximadamente } 3 \text { a } 10 \text { minutos (respeitando claramente os limites do usuário). } \\
\text { Poderão ser feitos na forma circular com a mão fechada (estilo ao apertar e girar de uma maçaneta redonda de } \\
\text { porta); na forma de massagem com os dedos; deslizando a palma da mão aberta; com a mão fechada apertando } \\
\text { e puxando para cima repetidas vezes; e assim por diante. A alternação do movimento é fundamental para que } \\
\text { toda a glande seja estimulada de diferentes formas e intensidades. }\end{array}$ \\
\hline $\begin{array}{c}\text { IV } \\
\text { Auto } \\
\text { percepção }\end{array}$ & $\begin{array}{l}\text { O procedimento deverá ser executado até que o toque se torne mais suportável do que quando iniciou. É } \\
\text { importante o usuário tomar consciência das possíveis contrações na musculatura de seu abdômen enquanto } \\
\text { o procedimento é executado. Essas contrações provocadas pelo prazer poderão sinalizar positivamente } \\
\text { a eficiência do método, uma vez que por meio delas o usuário estará liberando energia e cargas de tensão } \\
\text { excessivas acumuladas e que possivelmente estão ligadas ao disparo prematuro do reflexo ejaculatório. Caso o } \\
\text { usuário ejacule durante a execução do procedimento, fato possível de ocorrer (mas não frequente) deverá em } \\
\text { outra oportunidade reduzir a intensidade do procedimento, para depois intensificá-lo gradativamente conforme } \\
\text { sua auto percepção e condição para lidar com os diferentes níveis de prazer. }\end{array}$ \\
\hline $\begin{array}{l}\text { V } \\
\text { Penetração }\end{array}$ & $\begin{array}{l}\text { Depois de estimulado intensamente, o usuário deverá descansar entre } 2 \text { a } 5 \text { minutos, aproveitando o tempo para } \\
\text { normalizar sua respiração, trocar carícias, para só então em seguida, efetuar a penetração. Nesse momento, deve } \\
\text { estar atento a maneira pela qual sente o intercurso sexual, avaliando se percebe diferença em sua sensibilidade } \\
\text { e na urgência ou não de ejacular. Esperamos que logo nas primeiras tentativas, o usuário note significativas } \\
\text { alterações em sua capacidade de controle ejaculatório. }\end{array}$ \\
\hline
\end{tabular}

*Fonte: Elaborado pelo autor (2017). 
Favorêto (2002, p.326) afirma que após procedimentos de autoconhecimento corporal, espera-se que o homem tenha maiores condições de "administrar a sua excitação por meio de estímulos mais ou menos excitantes, o que consequentemente retardará sua ejaculação".

\subsection{Observações gerais acerca da execução da técnica}

De acordo com Kaplan (1975) e Favorêto (2002) é possível especular que o descontrole ejaculatório está diretamente relacionado ao excesso de sensibilidade genital. Tais indivíduos teriam dificuldades para perceber os sinais de sua excitação e as sensações que precedem a emissão espermática. Nesse sentido, Cândido e Mattos (2009, p.1) afirmam que "a prática de alguns exercícios faz com que as pessoas aprendam a liberar a couraça muscular, permitindo que o corpo funcione livre e naturalmente".

Reich (1998) descreve que estes pontos de tensão, chamados de couraça muscular, são semelhantes a terminais energéticos, onde a energia fica "represada". A dissolução dos referidos núcleos tencionais, por meio de procedimentos táteis, podem levar o indivíduo a sentir dores ou a sensação de sensibilidade.

De modo não diferente, sobre a glande do pênis possivelmente encontramos pontos de tensão, onde se acumulam maior quantidade de energia sexual. Esses pontos são altamente sensíveis e prazerosos ao toque, mas evidentemente desequilibrados em relação a outros pontos da glande. De acordo com Favorêto (2002, p.321) "a única forma conhecida de acúmulo de tensão que gera prazer é a sexual, na qual o próprio processo de excitação proporciona prazer e quanto maior a possibilidade de acúmulo de tensão" maior a urgência por sua descarga.

Esse desequilíbrio de sensibilidade provavelmente é o que de forma direta faz com que haja ejaculações inesperadas. A formação desses pontos pode se dar por diversas razões inclusive emocionais. Evidentemente a abstinência sexual pode ocasionar uma ejaculação rápida, mas como explicar as situações em que não há acúmulo de tensão sexual e mesmo assim o homem ejacula rápido? Nesses casos, fica mais ou menos claro que há uma conversão de energias emocionais e criativas para a modalidade sexual. Isto é, de acordo com Jung (2011, p.325) "da mesma forma que a sexualidade pode exprimir- se impropriamente através de fantasias, assim também uma fantasia criadora pode exprimir-se impropriamente através da sexualidade". Podemos supor que nessas situações há uma quantidade de energia criativa que busca ser realizada ou expressa e não encontrando outro caminho adequado, converte-se em energia sexual ou em urgência de realização (expressão criativa $=$ ejaculação rápida). Conforme Jung (2011) há que se ver o sintoma em seu aspecto supra-sexual, transcendendo o sentido real do fenômeno sexual para alcançar um sentido profundo e simbólico. Nesses casos, o controle da ejaculação somente será possível quando a situação emocional ou a causa primária for resolvida em psicoterapia ou por qualquer outro processo de autoconhecimento.

Para que haja equilíbrio sobre a capacidade ejaculatória toda a glande deverá se encontrar energeticamente balanceada, não podendo haver diferença de sensibilidade sobre ela. Podemos sugerir que o homem em um processo de autoexame com a ponta dos dedos molhados com lubrificante afira o balanço energético de sua glande, friccionando especialmente com o dedo polegar regiões mais fundas da glande e avaliando se nela contém pontos evidentemente mais sensíveis do que outros (que podem sofrer variações de acordo com os dias). Sobre a evidência de regiões mais sensíveis, recomendase com o toque dos dedos "esgotar" os pontos de tensão, liberando a energia contida e igualando a sensibilidade da glande como um todo.

O usuário precisará cientificar-se de que não deverá durante a execução do procedimento realizar movimentos de "sobe e desce" próprios da masturbação, isso possivelmente fará com que ele ejacule mais rápido. Essa atividade, como dissemos, pode ser feita pela parceira (o) durante as preliminares, mas durante as primeiras vezes recomendamos que o próprio indivíduo faça-a de maneira particular, afim de experimentar e tomar ciência das possíveis sensações novas, bem como de sua intensidade.

Ainda se deve orientar que durante a execução do autoexame dos pontos de tensão (sozinho), ele deverá descansar alguns minutos (entre 2 a 5 minutos) antes de se masturbar, com o intuito de perceber as mudanças em relação sensibilidade de sua glande. Em muitos casos, tempos depois nota-se que o equilíbrio de sensibilidade da glande se iguala de forma surpreendedora e quase instantânea. Os efeitos aumentam conforme o 
homem faz uso da técnica, que, aliás, consideramos de autoconhecimento. - Consegue fazer mais movimentos de "sobe e desce" do que usualmente? Ejaculou durante a execução do procedimento? Sente mais urgência em ejacular? Sente menos necessidade de ejacular? Sentiu contrações musculares? Sente-se mais cansado após a execução da técnica? Perdeu a ereção ou vigor? - Com efeito, da técnica, é possível ocasionar leve dificuldade de ereção ou para mantê-la, pois se compreende que com o exercício a energia de tensão excedente será eliminada.

Caso o usuário ejacule durante a execução da técnica (de maneira particular ou acompanhada), a mesma deverá ser inserida em outras oportunidades com menor intensidade. No entanto, pelo fato de não haver movimentos de bombeamento - que levam o esperma para dentro da próstata e consequentemente para sua breve emissão (RODRIGUES JR, 2004) - dificilmente o usuário sofrerá uma ejaculação durante a execução do procedimento, embora também não seja impossível conforme o grau de sensibilidade particular do reflexo ejaculatório de cada homem.

Durante a execução do procedimento o lubrificante deverá ser reaplicado sempre que secar ou quando houver necessidade. O usuário deverá estar ciente que não deverá fazer uso de sabonetes, condicionadores capilares e similares em substituição do lubrificante à base de água, sob o risco de provocar irritações, alergias ou lesões em seu órgão genital.

É importante que o usuário, dentro de uma cosmovisão que despatologiza o fenômeno da ejaculação rápida, saiba que o procedimento de massagem não gera efeitos permanentes, sendo necessário a sua contínua prática e manutenção. Acerca disso, Bestane et al (2002,p.90) considera que o cerne dos métodos de prescrição de exercícios corporais podem ser resumidos em treinamento através de etapas e graus de intensidade sucessivas, levando o paciente a um processo de autopercepção e controle de sua emissão ejaculatória. Propõe que "o controle do reflexo ejaculatório seja uma habilidade que possa ser treinada". Acredita que com treinamento adequado "a maioria poderá desenvolvêla em nível suficiente". Favorêto (2002, p.326) também salienta que "o tratamento da ejaculação precoce baseiase no aprendizado do controle voluntário da ejaculação". No entanto, os autores alertam que os procedimentos corporais não são aplicáveis a todos os casos de descontrole ejaculatório. Embora, em longo prazo, fazendo-se o uso frequente durante os processos de autoerotismo ou erotismo conjunto, espera-se que o homem habituese, dentro de um processo adaptativo, a elevados níveis de prazer, isto é, criando naturalmente uma espécie de capacidade de resistência a sensibilidade em sua glande. Supomos que quanto mais o exercício é praticado, mais o corpo tenderá suportar tensões.

Todo movimento deve se restringir unicamente sobre a glande do pênis. A intenção é dessensibilizála tirando as tensões provocadas pela ansiedade e pelo estresse do dia a dia. Baseamo-nos na teoria das couraças musculares de Reich (1998) para justificar a necessidade de eliminar os pontos de tensão sobre a glande com a finalidade de amenizar a velocidade do reflexo ejaculatório.

A técnica de início pode parecer contraditória, já que provoca intenso prazer. Mas se analisarmos de maneira crítica outros campos similares da física, tornase compreensível e até mesmo, evidente o raciocínio apresentado. Imaginemos ilustrativamente, que um sujeito que sente frio em uma piscina com água em temperatura ambiente de $20^{\circ} \mathrm{C}$, seja submetido por um período relevante a uma piscina com água em temperatura à $10^{\circ} \mathrm{C}$, isto é, sob uma temperatura ainda menor do que estava acostumado. Embora sinta frio, seu organismo se esforçará naturalmente rumo a um processo de adaptação frente a essa condição, de tal forma que ao retornar esse mesmo sujeito a outra piscina de temperatura ambiente à $20^{\circ} \mathrm{C}$, terá a impressão corporal de que a água "agora" é morna. Partimos da lógica que o sujeito que se habitua a altas doses de estímulo sobre sua glande, quando estimulado pela vagina ou ânus terá a sensação psicológica de que o estimulo é insuficiente ou fraco para fazê-lo ejacular. Aqui também podemos citar, conforme Conol et al. (2007), o conhecido caso de resistência de alguns homens em usar o preservativo durante as relações sexuais, sob a justificativa de que o preservativo, teria a capacidade de tirar a sensibilidade da glande do pênis. Ao retirar o preservativo sente-se mais prazer e consequentemente a ejaculação tende a ser um fenômeno mais breve.

Nesse sentido, o procedimento de massagem íntima poderá produzir com o tempo uma contínua resistência à estimulação, gerando a ideia de que o ato sexual provoca menos sensibilidade do que a ação da mão 
lubrificada; consequentemente tornando as sensações do ato sexual mais suportável e passível de se prolongar sem urgência de ejaculação. Conforme esse pensamento, o corpo não mais se satisfazendo com a leve estimulação vaginal ou anal, será motivado a se esforçar mais durante o ato sexual em busca de atrito para ativar a emissão ejaculatória.

O procedimento de massagem íntima deve ser executado antes da penetração vaginal ou anal, e nunca após a penetração como método de "socorro". Rodrigues Jr. (2004, p.188) alerta que "a estimulação manual deve ser feita para desenvolver o controle antes da emissão do esperma para dentro da próstata". Portanto, a técnica deve ser vista como preventiva e não corretiva. Isso porque, seu objetivo é provocar ou simular orgasmos secos, por meio de contrações musculares pélvicas e abdominais que liberam parte da energia libidinal excessiva de maneira semelhante às descargas orgásmicas. A esse respeito, a maioria dos indivíduos do sexo masculino sabe que frequentemente a primeira ejaculação pode ocorrer de maneira mais rápida do que uma segunda (isto é, quando o homem apresenta condições físicas para uma segunda ou mais emissão ejaculatória). Também sabem que a consistência da ereção e o interesse sexual diminuem significativamente após a primeira ejaculação. Mas se o corpo do homem tiver espasmos semelhantes ao orgasmo sem ejacular, parte da energia libidinal será despendida, mas o sêmen continuará guardado, garantindo a capacidade erétil.

As referidas contrações, possivelmente causam no corpo e no cérebro a impressão psicológica de ter cumprido o seu objetivo natural/biológico (liberação de tensões, orgasmo e fecundação quando se pauta na relação macho/ fêmea). Partindo do pensamento reichiano, supomos que procedimentos de massagem íntima podem fazer com que o indivíduo recupere o contato consigo mesmo, libere seus núcleos de energia reprimida nas estruturas musculares e nervosas, permitindo o funcionamento equilibrado de suas funções orgásmicas (REICH, 1998).

Nesse sentido, o procedimento além de ajudar no controle ejaculatório, pode também oferecer uma boa forma de inovação na relação a dois, uma vez que o referido procedimento de massagem pode ser estendido sem qualquer prejuízo ou contra indicação à parceira ou parceiro sexual. Caso o usuário por motivos particulares não deseje confessar a parceira(o) que o método direciona- se para a finalidade de adiar tanto quanto possível seu reflexo ejaculatório, diante da possibilidade de aplicação mútua do procedimento, poderá levá-lo para a vida íntima do casal como uma espécie de jogo sexual ou de brincadeira a ser realizada durante as preliminares.

\subsection{Possíveis efeitos adversos:}

De modo geral, por se equiparar nitidamente a uma manobra masturbatória, o procedimento não oferece riscos à saúde do usuário, mas se a técnica for executada em excesso (mais de uma vez ao dia e por demasiado tempo), de maneira agressiva ou sem a devida lubrificação poderá ocasionar: esfoliações sobre a glande (provocando ardência); dificuldade momentânea para manter a ereção uma vez que gera gastos energéticos durante a execução; e retardo demasiado da capacidade de orgasmo ou evitando a ejaculação em uma dada relação sexual.

\subsection{Casos em que a técnica poderá perder sua eficácia:}

A técnica poderá perder sua eficácia em casos comprovados de condições patológicas do sistema nervoso central ou de lesões na coluna vertebral; disfunção erétil por causa fisiológica ou psicológica; em outras condições psicológicas e psiquiátricas grave; em casos onde o homem se encontra há vários dias, semanas ou meses sem ejacular; e depois de iniciado o ato sexual, quando o orgasmo já houver sido evocado ou estiver muito próximo.

\subsection{Reações que podem ocorrer durante a execução do procedimento:}

É possíveis ocorrer durante a execução do procedimento: contração dos músculos abdominais e pélvicos; ejaculação involuntária; batimentos cardíacos acelerados; agitação motora provocada pelo prazer; e raramente micção involuntária quando feito de maneira demasiadamente intensa.

\section{Considerações finais}

O homem moderno, sustentado por valores de normalidade, tem patologizado tudo que não segue as tendências do modismo vigente. Frequentemente, uma 
patologia é definida pelo contexto histórico e situacional em que ela foi observada, sendo muitas vezes inexistentes em outros tempos e sociedades. Ponderamos que a ejaculação fora do tempo desejado não deve ser vista como uma disfunção da fisiologia humana. Consideramos que mais patológico e desproporcional é a tendência humana de enquadrar condições de sua natureza dentro de perspectivas reducionistas de normalidade. Cada sujeito é único e singular dentro de sua própria singularidade. A ecologia de um indivíduo não deve ser explicada pelos parâmetros de outro homem que não seja ele mesmo.

Nesse sentido, a terapia corporal apresentada nesse estudo tem a finalidade de promover o reencontro do usuário com sua própria natureza em um processo de autoconhecimento tátil e sensorial. Acreditamos na eficiência da técnica no processo de flexibilização dos núcleos tencionais do indivíduo encouraçado pelas diferentes emoções e condições que bloqueiam a livre expressão orgásmica, sendo, portanto uma técnica de liberação física e emocional. Partimos do pressuposto que o ejaculador prematuro tende a acumular altos níveis de tensão sobre a glande, sendo necessário desfazê-las para que haja a possibilidade de maior controle ejaculatório.

Ressaltamos que pelo fato de não ser invasiva ou prejudicial à saúde pode ser uma alternativa nas clínicas de sexologia, urologia e psicologia aos pacientes que se queixam de pouco controle ou que alcançam o clímax demasiadamente rápido durante as relações sexuais. No entanto, lembramos acima de tudo que o tempo de uma relação sexual jamais deve ser pautado pelo tempo de penetração durante uma relação sexual e sim pela capacidade de conexão entre a natureza dos pares que se inter-relacionam. Aliás, o procedimento descrito, pela possibilidade de aplicação mútua, sem contra indicação, pode favorecer a conexão entre o casal, inovando a relação e promovendo a superação do modelo "sexo sinônimo de penetração".

Não negamos a importância da indústria farmacêutica para o avanço da saúde humana, mas também não podemos ignorar a crescente utilização de medicação por parte da população em casos que poderiam ser evitados, poupando o corpo de cargas químicas que podem em longo prazo intoxicar o organismo e oferecer resultados inesperados. No caso da angústia pela tendência a ejaculação rápida, vemos frequentemente nos consultórios médicos a prescrição de antidepressivos e ansiolíticos que podem oferecer como efeito adverso o retardo ejaculatório, no entanto, também são comuns as queixas de que a medicação reduza a libido, tende a provocar a dependência química/psicológica e incômodos devido a capacidade sedação de alguns fármacos. Entre os usuários de medicações psicotrópicas, também encontramos relatos de que a medicação pode oferecer efeitos de retardo ejaculatório de curta temporalidade, perdendo a condição colateral esperada com o tempo.

Advogamos que o corpo enquanto espaço íntimo da ecologia individual deve ser desbravado para ampliação do autoconhecimento da totalidade do ser. Através dele o indivíduo toma ciência de seus limites e possibilidades. - Tocar o corpo, acariciar o corpo, é também tocar a alma e acariciar a alma. Isso porque corpo e mente não se tratam de organismos separados um do outro. O corpo reflete as expressões da alma e a alma sofre com os padecimentos do corpo. Investigar o corpo enquanto território de auto ciência e autoexame conferem ampliação de conhecimentos sobre si mesmo.

O conhecimento do corpo, isto é da natureza da materialidade humana, pode nos levar a um profundo conhecimento acerca do que ocorre também em nossa interioridade. Isto é, compreendendo a materialidade compreende-se também a espiritualidade e todo o campo que concerne aos processos psíquicos mais profundos. - Quem sabe a urgência ejaculatória não revele sobre o indivíduo aspectos de sua vida criativa que não achando outra forma de produzir-se e realizar-se se converte simbolicamente em sintomas somáticos. Quiçá a rapidez do referido reflexo revele sobre o homem a sua própria condição rítmica e desordenada de se relacionar e de lidar com os imperativos do dia a dia. Quem sabe tal agilidade esteja revelando o quanto o indivíduo precisa conectar-se si mesmo e aceitar-se ao invés de tentar seguir os padrões coletivos. A consciência corporal é consciência psíquica na medida em que revela o soma enquanto expressão da alma e vice-versa. O que de nossa vida emocional revela-se nos sintomas somáticos? - A condição corporal sempre será um sinal de como levamos a existência e de qual fase do ciclo da vida nos encontramos.

Mente e corpo formam um ciclo no qual qualquer um que se interesse pelo processo de 
autoconhecimento precisará esmiuçar todos os segredos a fim de se encontrar enquanto sujeito de singularidade e também de padrões coletivos. A mente se exprime no soma e o soma é veículo da mente. É parte do processo de autoconhecimento o campo de todas as sensações e sentidos captados por ele.

Consideramos que o estudo da emissão espermáticas antes do tempo esperado, bem como, qualquer outro estudo que envolva aspectos da sexualidade humana, ainda se encontra entre os temas negligenciados pela sociedade e pela própria academia que indiretamente, a nosso ver, se encontram envolvidos de valores e conservadorismo histórico. Nesse sentido, sugerimos que o tema seja levado para investigação em programas de pós-graduação stricto sensu em psicologia, sexologia, urologia e áreas afins.

O corpo por excelência é o palco da natureza humana. Nesta pesquisa o tomamos como ponto de partida para construção do (auto) conhecimento. Entendemos que o corpo deve ser conhecido e respeitado assim como qualquer outro sistema natural deve ser preservado para o perfeito funcionamento de sua totalidade. Enquanto ecólogos da alma, intuímos que cada manifestação do corpo, cada núcleo de tensão encontra-se estreitamente conectado aos diferentes aspectos da natureza psicológica dos indivíduos.

\section{Referências}

ABDO, C.H.N.; OLIVEIRA JR, W.M.; MOREIRA, E.D.; FITTIPALD, J.A.S. Perfil sexual da população brasileira: resultados do Estudo do Comportamento Sexual (ECOS) do Brasileiro. RBM rev. bras. Med. São Paulo, v.59, n.4, p.250-257, abr. 2002. Disponível em: http://www.moreirajr.com.br/revistas.asp?id materia $=1875 \&$ fase $=$ imprime

BARRETO, Antônio. Livro das simpatias. Belo Horizonte: RHJ, 1990.

BARROS, J. A. C. Pensando o processo saúde doença: A que responde o modelo biomédico. Saúde e Sociedade. São Paulo, v.11, n.1, p.67-84, jan, 2002. Disponível em: http://www.scielo.br/pdf/sausoc/v11n1/08
BEN-ZION, Izhak Zahi; GRUENWALD, Ilan; VARDI, Yoran. Sexualidade Masculina. In: TOLOKEN, Cláudio; ROS, Carlos Teodósio; TANNHAUSER, Mário. Disfunção Sexual. Rio de Janeiro: Revinter, 2004. p.0105 .

BESTANE, Walter; PAGANI, Eduardo; BARTOLO, Elaine Bestane. Fisiopatologia do controle ejaculatório. In: GLINA, Sidney; PUECH-LEÃO, Pedro; REIS, José Mário; PAGANI, Eduardo. Disfunção sexual masculina. São Paulo: Instituto H. Ellis, 2002. p.87-92.

CÂNDIDO, Paula Emanuela Fernandes; MATTOS, Daniela Junckes da Silva. Bioenergética: fundamentos e técnicas corporais. EFdeportes (Revista Digital), Buenos Aires, v. 14, n.131, abri. 2009. Disponível em: http:// www.efdeportes.com/efd131/bioenergetica-fundamentose-tecnicas-corporais.htm

CONOL, Maria Aparecida Tedeschi; ZAIAL, José Eduardo; NEVES, Fátima Regina Almeida; NEVES, Lis Aparecida Souza. O conhecimento de jovens universitários sobre AIDS e sua prevenção. Revista Eletrônica de Enfermagem: São Paulo, v. 09, n. 03, p. 748 - 758, 2007. Disponível em http://www.fen.ufg.br/revista/v9/n3/ v9n3a14.htm

DUARTE, Alisson José Oliveira. Ecologia da Alma: A natureza na obra cientifica de Carl Gustav Jung. Sociedade Brasileira de Psicologia Analítica (SBPA): São Paulo, v.35, n.1, p.05-19, jun/jul, 2017.

FAVORÊTO, Aparecida Vanini. Tratamento psicoterápico do descontrole ejaculatório. In: GLINA, Sidney; PUECHLEÃO, Pedro; REIS, José Mário; PAGANI, Eduardo. Disfunção sexual masculina. São Paulo: Instituto $H$. Ellis, 2002. p.321-328.

GROSSI, Fernanda Santos; LUCENA, Bárbara Braga; ABDO, Carmita Helena Najjar. Disfunções sexuais em homossexuais. Diagnostico \& Tratamento. São Paulo, v.20, n.1, p.38-41, 2015. Disponível em: http://files.bvs. br/upload/S/1413-9979/2015/v20n1/a4607.pdf 
JUNG, Carl Gustav. Psicologia do Inconsciente. Vol. 7/, $19^{\mathrm{a}}$ Ed. Petrópolis-RJ: Vozes, 2011a.

JUNG, Carl Gustav. A Natureza da Psique. Vol. 8/2, $8^{\mathrm{a}}$ Ed. Petrópolis-RJ: Vozes, 2011.

KAPLAN, Helena Singer. A nova terapia do sexo. Rio de Janeiro: Nova Fronteira, 1975.

KAPLAN, Helena Singer. Manual ilustrado da terapia sexual. São Paulo: Manole, 1984.

KINSEY, Alfred C. Sexual behav in the human male. Philadelphia, PA: WB Saunders, 1948.

MARTINS, Paulo César Ribeiro. O amante competente e outros campos do imaginário coletivo de universitários sobre dificuldades sexuais masculinas. 2007. 100f. Tese (Doutorado em Psicologia) - Universidade Católica de Campinas, Campinas-SP, 2007. Disponível em: http://www.bibliotecadigital.puc-campinas.edu.br/tde arquivos/6/TDE-2007-06-01T111823Z-1328/Publico/ Tese_Paulo_Martins-1a.pdf

MERLEAU-PONTY, Maurice. Ciências do homem e fenomenologia. São Paulo: Saraiva, 1973.

NOVARETTI, José Pedro Trevisan. Tratamento medicamentoso da ejaculação precoce. In: GLINA, Sidney; PUECH-LEÃO, Pedro; REIS, José Mário; PAGANI, Eduardo. Disfunção sexual masculina. São Paulo: Instituto H. Ellis, 2002. p.305-320.

PAIVA, Vera. A psicologia redescobrirá a sexualidade? Psicologia em Estudo, Maringá, v. 13, n. 4, p. 641-651, out./dez. 2008. Disponível em: http://www.scielo.br/pdf/ pe/v13n4/v13n4a02

POLAK, Ymiracy N. de Souza. A corporeidade como resgate do humano na Enfermagem. 1996. 135p. Tese (Doutorado em Enfermagem) - Universidade Federal de Santa Catarina Rede de Pós-Graduação em Enfermagem, Florianópolis-SC. Disponível em: https://repositorio. ufsc.br/bitstream/handle/123456789/112053/104921. pdf? sequence $=1$
REICH, Eva. Energia vital pela bioenergética suave. São Paulo: Summus, 1998.

RODRIGUES JR., Oswaldo Martins. Ejaculação Precoce. In: TOLOKEN, Cláudio; ROS, Carlos Teodósio; TANNHAUSER, Mário. Disfunção Sexual. Rio de Janeiro: Revinter, 2004. p.183-191.

Recebido em: 01/06/2017.

Aceito: 21/06/2017. 